\title{
En la carne del otro: cuerpo y alteridad según el pensamiento fenomenológico de Jan Patočka
}

\author{
Jaime Llorente Cardo ${ }^{1}$
}

Recibido: 7 de ebrero de 2018 / Aceptado: 19 de enero de 2019

Resumen. El presente trabajo se centra en las directrices fundamentales que guían la reflexión del fenomenólogo checo Jan Patočka a la hora de abordar la cuestión de la corporalidad, con el fin de situarlas en relación con el problema de la alteridad de los otros. Se trata, pues, en último término, de examinar en qué términos es posible una fenomenología de la intersubjetividad en la cual el cuerpo propio y el de los otros juega un decisivo papel, y de mostrar, a la vez, las limitaciones ligadas a tal punto de vista. Limitaciones referidas fundamentalmente a la excesiva relevancia concedida por Patočka al "cuerpo-objeto" en el marco de la alteridad intersubjetiva.

Palabras clave: Patočka, cuerpo, cuerpo subjetivo, cuerpo-objeto, alteridad, movimiento, intersubjetividad.

\section{[en] In the other's flesh: body and alterity according to Jan Patočka's phenomenological thought}

\begin{abstract}
The present work focuses on the key guidelines that direct the reflection of the Czech phenomenologist Jan Patočka when broaching the question concerning corporality, with the purpose of relating them in relationship with to the problem of the alterity of the others. So, ultimately, it's about examining on what terms a phenomenology of the alterity in which my own body and the others' body plays a decisive role is possible, and also showing, at the same time, the limitations linked with such point of view. These limitations are closely associated to the excessive relevance granted by Patočka to the "body-object" in the context of intersubjective alterity.
\end{abstract}

Keywords: real abstraction, idealism, materialism, commodity, social synthesis, transcendental subject.

Sumario. 1. Introducción. Entre la fenomenología de lo corporal y el don de lo intersubjetivo. 2. La aurora del pensamiento patočkiano acerca de la corporalidad: cuerpo y mundo natural. 3 . El cuerpo como sede del sentido: del cuerpo "experimentado" al cuerpo "experimentante". 4. La vida con los otros: un co-proyecto de naturaleza especular 5. Conclusión.

Cómo citar: Llorente Cardo, J. (2019): En la carne del otro: cuerpo y alteridad según el pensamiento fenomenológico de Jan Patočka, en Revista Anales del Seminario de Historia de la Filosofía 36 (2), 537-556.

$1 \quad$ IES “C. de Calatrava” (Ciudad Real).

jakobweinendes@gmail.com

https://orcid.org/0000-0002-6285-340X 


\section{Introducción. Entre la fenomenología de lo corporal y el don de lo intersubjetivo}

En el contexto del pensamiento fenomenológico contemporáneo, la cuestión relativa al modo de aparición y fenomenalización del cuerpo propio suele adoptar un papel si no crucial, sí al menos investido de decisiva pregnancia. Así ocurre, desde luego, en el caso de la "fenomenología de la carne" propuesta por Michel Henry, en la cual el "cuerpo subjetivo" -convenientemente deslindado, en su modo y ámbito de manifestación, del "cuerpo-objeto" material- se muestra como auténtica "sede de todos mis poderes", dado que "Nuestro cuerpo es el conjunto de poderes que tenemos sobre el mundo". ${ }^{2}$ Pero este rol fundamental asignado a la corporalidad en el seno de la fenomenología también resulta apreciable en el marco de formulaciones como la teoría Merleau-pontyana de la "subjetividad encarnada" o incluso en las someras indicaciones desgranadas por Heidegger en los Seminarios de Zollikon referidas a la esencia de lo corporal como "respuesta" que "corresponde" conductualmente a aquello que interpela al Dasein desde la apertura del mundo, cooperando así con ello en "el despliegue de su esencia" (Wesensentfaltung). ${ }^{3}$ En este contexto, la teoría acerca de la corporalidad derivada de la "fenomenología asubjetiva" propuesta por Jan Patočka constituye una propuesta no sólo suficientemente bien diferenciada de aquellas a las cuales venimos de referirnos, sino plenamente autónoma e innovadora en cuanto a sus tomas de posición concretas con respecto a éstas. ${ }^{4}$

2 Henry, M., Filosofía y fenomenología del cuerpo, Salamanca, Sígueme, 2007, p. 95 (en adelante FFC). Es desde esta perspectiva fundacional como Henry puede postular posteriormente - en Incarnation. Une philosophie de la chair-que: "cuando el continuo resistente opone a los poderes de nuestra corporeidad originaria una resistencia absoluta, este continuo define la realidad de los cuerpos que componen el universo «real». Cuando, al contrario, se somete a esos poderes, se revela en él la realidad de nuestro cuerpo orgánico. Es en esta sumisión a los poderes que componen el conjunto de nuestro «yo puedo» carnal, cuando el cuerpo orgánico se designa como el nuestro, como el que nos pertenece, a diferencia de los cuerpos que nos resisten absolutamente y que son los cuerpos ajenos" (Henry, M., Encarnación, Salamanca, Sígueme, 2001, p. 195. En lo sucesivo E).

3 Heidegger, M., Zollikoner Seminare, Frankfurt am Main, Vittorio Klostermann, 1987, p. 292. (En adelante ZS). Por lo demás, es de rigor recordar aquí que esta centralidad del fenómeno corporal aparece ya tempranamente -si bien no abordada aún desde un prisma estrictamente fenomenológico- en el pensamiento "neosocrático" de Gabriel Marcel, quien ya en 1918, al comienzo de Être et avoir, escribe: "La encarnación -dato central de la metafísica-. La encarnación, situación de un ser que aparece como ligado a un cuerpo [...]. De este cuerpo yo no puedo decir siquiera que es yo, ni que no es yo, ni que es para mí (objeto). De entrada, la oposición entre sujeto y objeto se halla trascendida [...]. Situación fundamental y que, en rigor, no puede ser dominada, sometida, analizada. Esta es precisamente la imposibilidad que se afirma cuando declaro, confusamente, que yo soy mi cuerpo, es decir: yo no puedo tratarme en absoluto como un término distinto de mi cuerpo, que estaría con él en una relación determinable" (Marcel, G., Ser y tener, Madrid, Caparrós, 2003, pp. 13-14).

4 En lo concerniente a la toma de posición con respecto a Heidegger, hay que señalar que difícilmente podía prever Patočka cuando en 1936 escribía, en referencia al carácter "excesivamente formal” de la ontología existencial heideggeriana, que "La praxis es ciertamente la forma original de la claridad, pero Heidegger jamás toma en consideración el hecho de que la praxis original debe ser principalmente la actividad de un sujeto corporal, que la corporeidad debe, pues, tener un estatuto ontológico que no puede ser idéntico a la ocurrencia del cuerpo como algo dado en presencia aquí y ahora" (Patočka, J., Le monde naturel comme problème philosophique, París, Vrin, 2016, p. 215. En adelante $M N P P$ ), el cariz de la respuesta dada por Heidegger a Medard Boss en 1972 al inquirir éste acerca del práctico soslayo de la cuestión de la corporalidad en Sein und Zeit. Tal respuesta reza como sigue: "Ahora todo aquello que llamamos nuestra corporalidad, hasta la última fibra muscular y la más oculta molécula hormonal, pertenece esencialmente al interior del existir; no es, entonces, fundamentalmente materia inanimada (leblose), sino que es un ámbito de ese poder-percibir no objetivable ni ópticamente visible de significatividades (Bedeutsamkeiten) de lo dado en el que consiste el Da-sein entero. Esto corporal (Leibliche) se configura, pues, de manera tal que puede ser utilizado en el trato (Umgang) con lo «material» inanimado y vivo de lo compareciente que se da" (ZS, p. 293). 
Otro tanto sucede en referencia a la cuestión de la relación intersubjetiva entre múltiples sujetos corporalmente encarnados; cuestión esta, la de la alteridad del otro (o de los otros), eminentemente ligada a la de la corporeidad propia, a la relativa a mi entidad somática particular. Mi carne parece remitir permanentemente a la carne ajena, a la carne del otro en tanto que ejemplificación remota de la alteridad que acaso preside la relación inmediata que yo mantengo con mi propia dimensión corporal. También en este caso, pensadores incardinados en mayor o menor medida en el círculo del pensar fenomenológico tales como Emmanuel Levinas o el propio MerleauPonty, han llevado la temprana intuición heideggeriana relativa al mit-Sein o "sercon [otros]" entendido como "existenciario" o estructura fundamental del modo de ser propio del Dasein, a terrenos muy alejados de aquellos en los que inicialmente fue localizada por el autor de Sein und Zeit. De este modo, Levinas sitúa el centro de gravedad de su pensamiento en la epifanía de un "rostro" fenomenológicamente invisible y no identificado ya con su mera presencia óntica que, no obstante, interpela al sujeto conminándolo a asumir su responsabilidad ética para con la miseria y la indigencia del prójimo (autrui).

Por su parte, Merleau-Ponty postula que "el cuerpo del otro" se muestra fundamentalmente como "el primer objeto cultural, aquel por el cual todos ellos existen" y que es captado, ante todo, en términos de "portador de un comportamiento". ${ }^{5}$ De hecho, explicitando palmariamente las dos cuestiones que aquí nos interesan, MerleauPonty escribe significativamente en el capítulo dedicado a la alteridad y "el mundo humano" en Phénoménologie de la perception que: "es justamente mi cuerpo el que percibe el cuerpo del otro y encuentra en él como una prolongación milagrosa de sus propias intenciones, una manera familiar de tratar con el mundo; en adelante, como las partes de mi cuerpo forman conjuntamente un sistema, el cuerpo del otro (autrui) y el mío son un único todo, el anverso y el reverso de un único fenómeno, y la existencia anónima de la que mi cuerpo es, en cada momento, la huella (trace), habita en lo sucesivo estos dos cuerpos a la vez" ${ }^{6}$ También en referencia a la cuestión de la esencia de la alteridad intersubjetiva, los fragmentarios textos fenomenológicos de Patočka tienen acaso una cardinal y determinante palabra que decir. Una palabra tal vez en exceso desoída y preterida por el pensamiento fenomenológico hodierno y que quisiéramos seguidamente poner de relieve en cuanto a su trascendencia y a sus implicaciones en el marco de la filosofía contemporánea.

\section{La aurora del pensamiento patočkiano acerca de la corporalidad: cuerpo y mundo natural}

Ya en el marco de su primera obra filosófica, El mundo natural como problema filosófico (1936), Patočka reconoce abiertamente el carácter decisivo que revisten, desde el punto de vista fenomenológico, los fenómenos del cuerpo propio y de la alteridad de los otros, haciéndolos resaltar sobre el fondo común representado por la manifestación de las entidades naturales: "El problema de la realidad en la aparición no se plantea únicamente en relación con la naturaleza objetiva. Hay un problema análogo en nuestra relación con nosotros-mismos, con nuestro propio fondo cor-

Merleau-Ponty, M., Fenomenología de la percepción, París, Gallimard, 1992, p. 401. En lo sucesivo PhP. PhP, p. 406. 
poral instintivo con el cual debemos explicarnos; y hay un problema análogo en nuestra relación con los otros, con cuya realidad hemos de tratar a la vez interior y exteriormente". ${ }^{7}$ La tarea de una posible ontología fenomenológica incluye, pues, incontestablemente, la elucidación de los respectivos "modos de ser" (es decir, de "aparecer" propios de la corporalidad y de la alteridad intersubjetiva.

En lo que respecta a la particular modalidad fenomenológica propia del cuerpo, en esta fase inicial de su pensamiento Patočka parte ya de un supuesto fundamental, a saber: aquel conforme al cual los estados corporales, las Erlebnisse sensoriales o internas, preceden radicalmente a la apertura que la percepción extiende sobre el mundo objetivo. Lejos de que las sensaciones particulares "empíricas" activen la actividad somática, ésta antecede a aquéllas y las determina de modo apriórico al margen de toda experiencia perceptiva efectivamente dada. Es en esta tesis capital donde Patočka descubre "uno de los principales rasgos de nuestra experiencia original en el mundo natural": "la localización de las vivencias en el cuerpo, localización que es inmediatamente dada y que precede a toda experiencia perceptiva. La acción operante en el cuerpo no es dada por las impresiones singulares; al contrario: ella las precede". ${ }^{8} \mathrm{Al}$ lado de esta prelación del actuar corporal inmediato con respecto a las "afecciones externas" empíricamente captadas, Patočka localiza otro rasgo que define esencialmente a la corporalidad propia de todo ser viviente inserto en el mundo natural: la pertenencia a una corporeidad en virtud de la cual tal ser interactúa ininterrumpidamente con los "objetos" que pueblan su entorno (inicialmente con las cosas presentes en su Um-welt próximo y potencialmente con la totalidad de las cosas). No resulta posible ni pensable postular un ser humano carente de corporeidad o privado del cauce comunicativo que su entidad corporal le procura al intermediar entre él mismo y su mundo circundante. Aquí surge y se perfila un límite decisivo en lo referente a la determinación de la esencia de lo humano, puesto que, al decir patočkiano, es precisamente la corporeidad la instancia que sitúa al sujeto humano en la esfera de la interacción causal recíproca entre él mismo y las cosas que lo circundan. Y es justamente la presencia de tales objetos circundantes la que traza límites, fronteras y barreras que, al imponerse al sujeto, le muestran con nitidez su condición esencialmente finita. Así pues, la condición corporalmente encarnada de la subjetividad aparece, a esta luz, como el auténtico y más conspicuo factor configurador de la finitud humana. Una finitud que, a diferencia de lo que sucede en el caso del animal, es únicamente conocida y comprendida por el individuo humano en tanto que éste no constituye una mera "cosa entre las cosas", sino fundamentalmente un ser cuya esencia reside en "saber de esta situación que es la suya". 9

Y, no obstante, el joven Patočka se apercibe ya en este estadio temprano de su pensar fenomenológico, de que el modo de constitución propio de la corporalidad se hurta únicamente de manera parcial al modo general en virtud del cual se constituyen los elementos "objetivos": las cosas efectivamente dadas. Ese carácter parcial se muestra como la genuina raigambre de la capital distinción asentada por Patočka entre dos posibles modalidades de experiencia de lo corporal. Por un lado, una vivencia

\footnotetext{
$M N P P$, p. 181.

$M N P P$, p. 188. A este respecto, Henry no deja de llevar a cabo una aproximación muy semejante a la "condición fenomenológica" de la corporeidad cuando alude a "este cuerpo previo a la sensación, previo al mundo, que se diferencia de los cuerpos del universo en que no opone al «yo puedo» más que una resistencia relativa" (E, p. 195).

MNPP, p. 89.
} 
inmanente, "interna", centrada en la disposición innata del cuerpo, desde la cual éste aparece fundamentalmente como el "medio de las kinestesias" (percepciones de la localización espacial y el movimiento de los distintos elementos somáticos) en cuyo interior ubicamos "todas nuestras afecciones resultantes del comercio con las cosas". ${ }^{10}$ Por otro, una experiencia de la corporalidad eminentemente "externa", en la cual el cuerpo aparece como una "cosa" cuya presencia y cercanía se deja sentir de forma constante y cuyo modo de darse (claramente "objetivo") resulta análogo al resto de los objetos y hechos intramundanos. Repárese en el hecho de que esta "doble experiencia del cuerpo" puesta de relieve por Patočka viene a coincidir en lo esencial con la distinción, heredada de Maine de Biran y reelaborada por Henry, entre "cuerpo subjetivo" y "cuerpo-objeto", esto es, entre un "cuerpo trascendental" entendido como núcleo central al que remite todo "yo puedo" y un "cuerpo objetivo" (material) que se fenomenaliza en paralelo a los elementos que pueblan y configuran el "mundo objetivo" externo. Un mundo, al decir de Henry, absolutamente extraño a la vida inmanente auto-afectada de modo inmediato y al pathos en virtud del cual ésta se manifiesta en su propio dominio subjetivo de fenomenicidad. En cualquier caso, si el sujeto encarnado dispone de su propio "mundo exterior" y es capaz, por tanto, de mantener una relación de disposición inmediata con respecto a las cosas que incluye el poder de ejercer dominación sobre ellas, ello se debe a la previa donación de la experiencia de la corporalidad. En ausencia de tal experiencia originaria del cuerpo, ni siquiera nos hallaríamos en disposición de hablar propiamente de "apertura al Ser", "trascendencia" o "intencionalidad" alguna en referencia a la esencia de la relación entre el sujeto humano y el mundo. ${ }^{11}$

Además de lo anterior, si la noción clave a la hora de aprehender la existencia como tal no es otra que la de "movimiento" -como Patočka postula ya en este momento liminar y mantendrá posteriormente como idea matriz de su pensar fenomenológico-, este movimiento significa, una vez más, ante todo que "la existencia es esencialmente corporal". ${ }^{12}$ Lejos, pues, de seguirse de la situación "existencial" concreta en la cual el sujeto se encuentra de modo constitutivo en todo momento, todas sus actividades y afecciones, bien se trate de fenómenos de orden afectivo, conductual o creativo ("activos" o "pasivos", por tanto), revisten un carácter absoluta y plenamente corporal. Algo muy semejante es lo que postula el último Heidegger, como hemos tenido oportunidad de constatar. A ojos de Patočka, este hecho de que toda nuestra posible acción (y pasión) se halle ya siempre investida de una esencial corporeidad, determina el que todo actuar comparezca siempre en términos de tránsito acontecido entre un terminus a quo y un terminus ad quem, es decir, como mo-

\footnotetext{
MNPP, p. 118.
}

11 En este sentido, observa Patočka: "En tanto que este medio de la disponibilidad, este a través de lo cual se realiza todo nuestro comercio con la realidad, la corporeidad es siempre originalmente atemática: la atención se dirige a las cosas de las cuales disponemos y de las que nos ocupamos, más bien que a la disposición como tal" (MNPP, p. 118)

$12 M N P$, p. 227. Así, por ejemplo, en el ensayo El mundo natural y la fenomenología, redactado hacia 1967, y postulando un vínculo esencial entre corporalidad propia y alteridad del otro, escribirá Patočka: "la orientación de nuestro movimiento siempre tiene lugar desde la corporalidad; los poderes en cuyo seno se desenvuelve el movimiento son el referente del propio movimiento; y su rasgo característico en cuanto movimiento se manifiesta al discurrir en las modalidades del enraizarse, del prolongarse a uno mismo a base de ir perdiéndose y del autoconquistarse en la exposición al peligro; modalidades que tienen todas ellas una vertiente temporal y una vertiente de relación con el otro" (Patočka, J., El movimiento de la existencia humana, Madrid, Encuentro, 2004, p. 51. En lo sucesivo $M E H)$. 
vimiento desde un inicio hacia un fin o meta determinados. ${ }^{13}$ Es merced a tal corporeidad, por tanto, como el movimiento de la existencia humana es inextricablemente entreverado con "las grandes potencias que contribuyen a formar, con anterioridad a toda objetidad singular, la naturalidad de la naturaleza". ${ }^{14}$

Aquí, en este punto, es donde tiene lugar el tránsito "lógico" entre la teoría de la corporalidad patočkiana y su perspectiva concerniente al fenómeno de la intersubjetividad, dado que ese "mundo natural" constituye precisamente, al decir del fenomenólogo checo, "aquello que aporta consigo, a través de su estructura ontológica, el «ser-con» humano [el mit-Sein heideggeriano] fundado en última instancia sobre las dos grandes posibilidades de la temporalización". ${ }^{15}$ No deja de resultar significativo el hecho de que, casi treinta años después de consignar estas palabras, en su curso Introducción a la fenomenología de Husserl dictado en Praga en 1964-1965, Patočka mantenga prácticamente intacto ese postulado nexo esencial entre corporalidad e intersubjetividad. ${ }^{16}$ De hecho, matizando y modificando a su modo la teoría husserliana de la alteridad de los otros desde la distinción establecida entre "cuerpo-sujeto" y "cuerpo objeto", declara allí: "Según esta modificación, la experiencia del cuerpoobjeto juega precisamente un rol de primer orden en la experiencia del prójimo. No es sino sobre la base de la experiencia del cuerpo-objeto como yo devengo cosa entre las cosas, como me sitúo al mismo nivel que los objetos que se presentan en mis perspectivas. La experiencia del cuerpo-objeto, la experiencia de si en tercera persona $[. .$.$] , adquiere una importancia central en lo concerniente a la experiencia$ del otro en tanto que sujeto, él también, de una experiencia propia". ${ }^{17}$

13 De esta forma, "En virtud de la corporeidad, nuestra existencia está siempre, en su acción, cargada del peso de la necesidad, de la repetición, de la restitución y del prolongamiento de la corporeidad propia. El círculo de la existencia [...] implica siempre en cierto modo el círculo de la vida que cumple las funciones vitales con el fin de retornar a sí misma" (MNPP, p. 227).

$14 \quad M N P P$, p. 227.

$15 M N P P$, p. 258. Como señala oportunamente al respecto Iván Ortega Rodríguez: “para que el otro, en cuanto, otro, pueda realmente aparecer, hace falta que haya una cierta continuidad. Esta continuidad, que al tiempo es medio del aparecer del otro, como realmente otro, ha de ser una continuidad no subjetiva, pero directamente relacionada con la subjetividad vivida. Este tipo de continuidad la encuentra Patočka en el cuerpo como objeto, éste se presenta en la vivencia, pero se presenta como diferente del cuerpo vivido. Así pues, el cuerpo como cuerpo-objeto es el que abre a experimentar al otro como otro" (Ortega Rodríguez, I., "Cuerpo y fenomenología «asubjetiva» en Jan Patočka", Investigaciones fenomenológicas, no 8, 2011, p. 166).

16 Un vínculo reconocido, asimismo, por una fenomenología tan distinta a la de Patočka como la de Marc Richir: "el cuerpo fenomenológico como cuerpo vivido (o vivir encarnado) forma parte integrante del exceso del vivir sobre lo vivido [...]. Juega incluso, tal y como lo ha mostrado Husserl, un papel clave en el encuentro interhumano, también llamado «intersubjetivo», y es ahí, asimismo, donde más se revela como un ser de sentido y de lenguaje, más allá de los enunciados lingüísticos que puedo proferir o entender del otro" (Richir, M, El cuerpo, Madrid, Brumaria, 2015, p. 101. En adelante EC).

17 Patočka, J., Introduction à la phénoménologie de Husserl, Grenoble, Millon, 1992, p. 198 (en adelante IPH). En ese mismo curso, Patočka clarifica meridianamente la dualidad del cuerpo propio puesta de relieve por el análisis fenomenológico de la siguiente forma: "Hay, por una parte, el cuerpo-sujeto, el cuerpo que siente, que «puede» y que realiza activamente sus posibilidades, el cuerpo solicitado en todo momento por sus necesidades e inserto en el marco previo de los instintos. Por otra parte, el cuerpo-objeto, el cuerpo sentido y dado en los campos sensoriales de la distancia. Por una parte, el cuerpo en tanto que objeto originario de la proximidad, «objeto» totalmente excepcional, extra-ordinario; por otra, el cuerpo que se encuentra al mismo nivel que todas las demás objetidades. Por una parte, el cuerpo en primera persona; por otra, el cuerpo en tercera persona" (IPH, pp. 191-192).

Con todo, Patočka no deja de reconocer, en otro de sus más relevantes cursos, la preeminencia casi exclusiva de la "tercera persona" a la hora de abordar históricamente la cuestión de la corporalidad. Una práctica exclusividad que se deja sentir tanto en el marco de la filosofía antigua como en el contexto del pensamiento moderno: "En el pensamiento griego encontramos solamente una perspectiva externa del cuerpo humano". [Aristóteles] 
Repárese en que aquí Patočka no cifra la matriz de la intersubjetividad ni localiza el núcleo propiciador del acceso a la alteridad del otro en el "cuerpo sujeto" o "cuerpo interno", sino justamente, de modo explícito, en el "cuerpo-objeto" externo y "objetivo". En el cuerpo cuya fenomenalización acontece precisamente en el seno de ese "mundo natural" en cuya constitución ontológica el Patočka de 1936 reconocía, como hemos visto, el auténtico germen del "ser-con" intersubjetivo. En este decisivo aspecto, el pensamiento fenomenológico de Patočka discurre claramente por derroteros muy diferentes a los asumidos por la fenomenología de la alteridad propuesta -mencionando el más conspicuo ejemplo al respecto- por Emmanuel Levinas. En el marco de esta "fenomenología heterodoxa", en efecto, ni siquiera puede hablarse del modo apropiado de "abordar" o "acceder" al otro, sino que el sujeto está siempre ya "de golpe" e inmediatamente concernido por el otro, no siendo jamás indiferente a él. Pero esta intersubjetividad inmediata tiene lugar a partir de la epifanía del rostro ajeno. Un rostro que, sin embargo, no se identifica con la materialidad facial objetiva (con una región determinada del cuerpo, en suma), sino que se revela como apelación y llamada a la responsabilidad ética situada al margen de la presencia física (corporal) del rostro. El rostro, apunta Levinas, no es "esta nariz, estos ojos o esta barbilla" (la corporeidad "objetiva"), sino un sustrato no directamente visible cuyo modo de fenomenalización nada tiene ya que ver -al contrario de lo que sucede en Patočka- con la manifestación del "cuerpo-objeto". En nuestras conclusiones tendremos ocasión de incidir nuevamente sobre este decisivo aspecto.

En cualquier caso, lo cierto es que, desde esta primeriza toma de posición que Patočka ya no abandonará jamás, la corporeidad constituye a sus ojos el elemento a través del cual el sujeto entra en contacto con los objetos mundanos y establece, ante todo, relaciones vitales con otros sujetos diferentes a sí mismo. De hecho, uno de los rasgos constitutivamente definitorios de la esencia de lo humano reside precisamente en la capacidad para comprender a otros seres vivientes próximos a uno mismo, siendo quien comprende en todo momento consciente de tal acto de comprensión. La humanitas del homo no radica acaso sino en esta facultad del "ser-con" o "vivir-con" consciente de sí misma, dado que el existir humano se despliega y se vive siempre con respecto a los otros, en perpetua remisión al prójimo. La vida humana se define merced a su condición de signo constantemente referido al otro, alusivo a la alteridad del otro. La vida humana no es algo que se viva, pues, "para sí", en bucle replegado "sobre" o "en" sí mismo, sino que, además de referir estructuralmente a los demás sujetos, es siempre vivida en el contexto de un mundo comúnmente compartido por todos. Un mundo colectivamente experimentado que, lejos de mostrarse en términos de ámbito donde acontece cada particular actividad humana, aparece más bien como "un medio que es actualmente accesible a diferentes individuos en los más diversos

contempla el cuerpo como una cosa accesible a la percepción, a una distancia, no como mi cuerpo. En la filosofía antigua, psychē no es nunca comprendida como un sujeto [...], sino siempre en tercera persona, impersonalmente, como una función vital [...]. En la filosofía antigua no hay subjetividad, toda ella está en tercera persona" (Patočka, J., Body, Community, Langage, World, Illinois, Open Court, 1999, pp. 5-8). Por su parte, igualmente, en la aurora del pensamiento moderno, "Descartes comienza con la autoconciencia, la conciencia del Yo, pero la atención de la reflexión filosófica es enseguida distraída, una vez más, desde la personalidad hacia algo objetivo, impersonal, hacia una sustancialidad metafísica. Por esa razón, el problema del cuerpo subjetivo permaneció sin desarrollar durante tanto tiempo. Descartes descubrió el problema de la corporalidad subjetiva, pero justo después de ese descubrimiento lo encubrió de nuevo" (Ibíd., p. 10). 
grados, siendo en todo momento principalmente accesible a todos al mismo título intersubjetivo". ${ }^{18}$

La comprensión del otro en "ciertos rasgos generales" - bien se trate de un sujeto cercano o de un extraño totalmente desconocido- acontece, por tanto, según el pensador checo, siempre gracias al hecho de que él presenta una corporalidad absolutamente análoga a la nuestra. En virtud de tal parangón el sujeto experimenta la vívida impresión de ser capaz de actuar llevando a cabo las mismas acciones que ve efectuar al otro, lo cual no hace sino confirmar el postulado patočkiano conforme al cual "El otro es una de las primeras categorías materiales y una de las más importantes. Solamente es quizás más originaria la categoría de la cosa de uso práctico, la cual se constituye como instrumento pasivo de nuestra acción". ${ }^{19}$ Así, la experiencia del "otro yo", del alter ego trascendental, no nos es dada más que de forma indirecta, puesto que se trata de una experiencia derivada de una "experiencia de constitución" cuya donación no depende de ser efectivamente operada por el sujeto. Ese modo indirecto de darse el otro es realmente "un cierto modo de apresentación por el cual yo «proyecto» un vivir de experiencia análogo al mío en una corporeidad, también ella, análoga a la mía". ${ }^{20} \mathrm{El}$ alter ego dado en la "apresentación" comparece, en el marco de la "actitud natural", como un ente tan transido de limitación y finitud como lo es el ego mismo, mientras que, contemplado desde la perspectiva trascendental, adquiere el sentido de una constitución diferente de la mía, de la propia de este ego, dado que aquí es la subjetividad propia la que se impregna del sentido de la constitución. Así pues, considerada desde el prisma de la fenomenología, pertenece constitutivamente a la subjetividad individual el acto de constituir ella misma a las subjetividades ajenas ("mónadas", prefiere llamarlas Patočka); un hecho que define el ámbito de lo subjetivo como un reino trascendental constituido por subjetividades particulares ("mónadas") que llevan a cabo el acto de la constitución de manera común, simultánea y "armónica". Únicamente esta "constitución intersubjetiva" puede suministrar e imponer leyes a la existencia en el marco de una esfera fenomenológica donde "la constitución es una co-constitución". ${ }^{21}$

Pero aún resta un factor crucial a la hora de elucidar la conexión entre corporeidad y alteridad del otro, a saber: el fenómeno de la palabra significativa, de la comunicación lingüística. En efecto, al final de su primera obra Patočka considera ya que la proximidad intersubjetiva propiciada por la apercepción de los otros, del prójimo, se halla en la raíz misma de la configuración del lenguaje y aparece como su presupuesto necesario, como su principal condición de posibilidad. Ahora bien, los vínculos que yo pueda establecer con respecto al otro han de pasar forzosa e inapelablemente por la consideración de su entidad corporal, esto es, por su corporeidad concreta captada como epifanía o manifestación expresiva de una subjetividad viviente que no se muestra ella misma en el campo de los fenómenos "externos". En este sentido, postulando la inevitabilidad de proyectarse en cierto modo hacia la car-

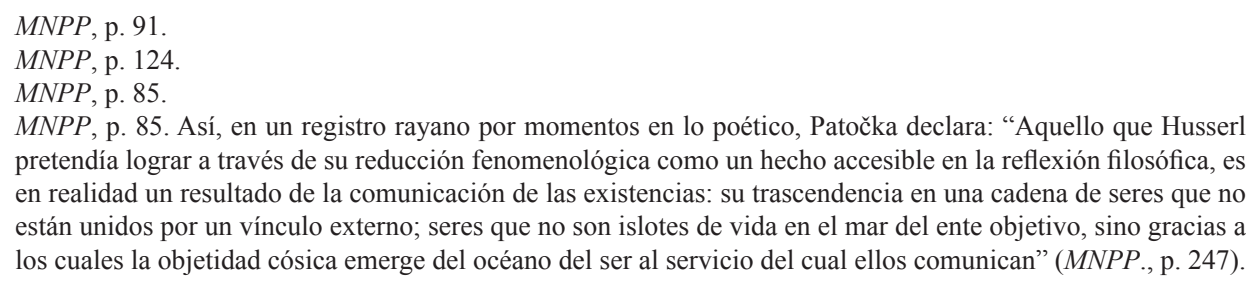
pretendía lograr a través de su reducción fenomenológica como un hecho accesible en la reflexión filosófica, es en realidad un resultado de la comunicación de las existencias: su trascendencia en una cadena de seres que no están unidos por un vínculo externo; seres que no son islotes de vida en el mar del ente objetivo, sino gracias a los cuales la objetidad cósica emerge del océano del ser al servicio del cual ellos comunican” (MNPP., p. 247). 
ne del otro, escribe Patočka: "la otra persona es, en su corporeidad, siempre un fenómeno expresivo. Yo no puedo hallarme en contacto con ella sin explicar su corporeidad como manifestación de sus vivencias". ${ }^{22}$ De este modo, con anterioridad a toda tentativa concreta de comunicación intersubjetiva, ya nuestra estructural remisión al "ser-con" -nuestra vida efectiva con los otros- nos sitúa en posesión de un previo saber acerca del prójimo. Es, pues, en virtud de esta originaria predisposición hacia la acción conjunta con los otros, sobre el fundamento de esa prístina inclinación a "la afirmación de sí en el seno de una colectividad", como tiene presumiblemente lugar la génesis de la comunicación intersubjetiva. Una apelación o "mención" al otro que no persigue, en última instancia, sino el acceso efectivo a su interioridad con el fin de influir sobre ella (de incidir sobre los pathēmata de su psykhē, diría Aristóteles) adecuándola a las aspiraciones propias de nuestra voluntad. La palabra dotada de sentido cumple -y sólo ella puede hacerlo- esa función "alérgica" 23 y persuasiva, residiendo, pues, en tal función aquello que Patočka designa como su "obra social". Obra que el pensador eslavo define sucintamente como "la acción ejercida sobre los otros por medio del contenido de aquello que es expresado". ${ }^{24}$

En este primer estadio del itinerario fenomenológico de Patočka, el cuerpo asume ya el estatuto de elemento mediador entre sujeto y mundo, entre lo humano y las cosas, adoptando, asimismo, el rol de instancia garante del "ser-con", de la socialidad intersubjetiva. Comprobemos, en lo sucesivo, como esta intuición auroral se diversifica en el transcurso de la rapsódica producción patočkiana adquiriendo nuevas dimensiones de sentido al ser aplicada a contextos que se hallan inicialmente ausentes en el período liminar de su pensamiento.

\section{El cuerpo como sede del sentido: del cuerpo "experimentado" al cuerpo "experimentante"}

En los ensayos y cursos transmitidos de forma fragmentaria -como la práctica totalidad de su producción- y datados en las décadas de los sesenta y setenta del pasado siglo, Patočka vuelve sobre la cuestión de la corporalidad imprimiéndole un marcado sesgo "situacional" a la vez que intersubjetivo. ${ }^{25}$ Un cariz probablemente deudor y derivado de las tesis relativas al "primer movimiento de la existencia humana": aquel que, conforme a los postulados asentados por el fenomenólogo eslavo, propicia el originario "anclaje" o "arraigo" en virtud del cual el sujeto es "aceptado" en el seno de lo existente. Este "estar-en situación" remite al hecho de hallarse situado, orientado, inserto en la trama del mundo (y en la relación con los otros) merced a la "posesión" de un cuerpo vivo. La corporalidad asume, pues, el estatuto ontológico

$22 \quad M N P P$, p. 140.

23 "Alérgica" en sentido etimológico: como "efecto" (érgon) causado o inducido a otro (állos). Un término particularmente oportuno en este contexto, dado que, según Patočka: "La comunicación nace como una acción ejercida sobre el otro por nuestra propia expresión; acción deliberada, pero que puede, no obstante, ser directamente comprendida a partir de la situación" (MNPP, p. 141).

$24 \quad M N P P$, p. 136.

25 En palabras de Karel Novotný: “A partir des années 1960, Patočka défend expressément une position qui regarde le corps propre, non pas comme quelque chose qui relèverait de l'ego selon un rapport de concomitance ou de coordination, ou encoré à la manière de deux processus objectifs parallèles et correspondants, mais comme identique au subjectif dans l'expérience du monde" (Novotný, K., La genèse d'une hérésie. Monde, corps et histoire dans la pensée de Jan Patočka, París, Vrin, 2012, p. 59. En lo sucesivo GH). 
de órganon mediador a través del cual el sujeto ejerce actos de causalidad (efectos) sobre el mundo circundante modificando su configuración por obra de la actividad práctica (el Zupacken, Formen y Umformen de los que habla Heidegger en Zollikoner Seminare) ${ }^{26}$ Nuestra condición de conciencia ligada a una carne constituye, asimismo, el factor clave subyacente al hecho de que la subjetividad viviente utilice los elementos y objetos mundanos ("externos" a ella) como instrumentos o medios destinados a la satisfacción de las necesidades demandadas por la vida corporalmente encarnada. ${ }^{27}$ De este modo, si es cierto, como apunta Patočka al comienzo de sus Lecciones sobre la corporeidad, que "El hombre tiene necesidad de saber dónde está [...] para reconocerse en el lugar en el que mora, para poder trabajar, cumplir sus deberes más esenciales y desempeñar roles sociales siempre también espacialmente articulados", ${ }^{28}$ entonces esa requerida orientación tiene lugar fundamentalmente a través del cuerpo entendido como instancia subjetiva y definida por la actividad. ${ }^{29}$

Cuerpo subjetivo, pues, desvelado como instancia donadora de sentido, proveedora de ubicación y afianzamiento en lo ente, pero concebido no en calidad de objeto cuya función espacial se sustancie en forma de relaciones objetivas o determinaciones somáticas de orden "reificado", sino como elemento viviente. El cuerpo propio, lejos de fenomenalizarse en términos de "cosa" situada en un plano ontológico de igualdad con respecto a las cosas situadas en el espacio objetivo, despliega su manifestación como "una vida que, por sí misma, es espacialmente, que produce su propia localización, que se convierte ella misma en espacial. ${ }^{30}$ Es debido a este modo peculiar de fenomenalización suyo, que el cuerpo subjetivo (personal) no se da en el modo de aparecer de la cosa, no se localiza como "cosa entre las cosas", sino que, más bien, aparece como un "cuerpo viviente" cuya función primordial consiste en señalar nuestra situación general "en algún lugar" y en indicar "dónde" nos hallamos en particular. ${ }^{31}$ Pero esta función localizadora desempeñada por la corporalidad se encuentra, indica Patočka siguiendo a Husserl, indisolublemente aherrojada al

26 En efecto, si, como indicamos al comienzo, según Heidegger estamos esencialmente emplazados a corresponder de manera práctica a aquello que nos interpela desde nuestra constitutiva apertura al mundo, entonces "el hombre no podría hacer tal cosa si él solamente consistiese en un percibir «espiritual» ('geistigen'Vernehmen), si no fuera también de naturaleza corporal. ¿Cómo habría entonces de ser posible un actuar manual (Zupacken), un formar y deformar (Formen und Umformen) otros elementos dados (Gegebenheiten) vivientes o inanimados «materiales» que salen al encuentro (begegnender)?” (ZS, pp. 292-293). En todo caso, desde la perspectiva asumida por Patočka (y, a nuestro juicio, con acierto): "La doctrina de Heidegger es incapaz de explicar tanto el cuerpo propio como la socialidad: la relación con el otro como momento esencial de la existencia" (Patočka, J. Papiers phénoménologiques, Grenoble, Millon, 1995, p. 79. En lo sucesivo PP).

27 Así, en el ensayo El mundo natural y la fenomenología, redactado hacia 1967, Patočka escribe: “Orientación y situación remiten a la corporalidad. En este sentido corporalidad significa corporalidad práctica, libre: pues sólo por mediación del cuerpo, de un cuerpo sobre el que ejercemos un poder inmediato, podemos tener actividad en el mundo y tomar parte efectiva en la transformación de las cosas que contiene. Pero, por otra parte, la corporalidad es igualmente orientación en el sentido de que las necesidades del cuerpo hacen que la vida se tome a sí misma como fin y que se sirva de las objetividades como medios para este fin" (MEH, p. 33).

28 PP, p. 61.

29 Lo cual no implica que se trate de una exclusiva orientación hacia el cuerpo propio, puesto que: "El centro de referencia de la orientación corporal se encuentra fuera del cuerpo propio. Toda orientación es orientación de nuestra acción, de nuestra intervención corporal activa, y esto requiere de un referente. El referente de nuestra corriente efectuadora, realizadora [...], es un sustrato inmóvil y permanente: la Tierra" (MEH, p. 33).

$30 \quad P P$, p. 59.

31 Es por ello por lo que, inversamente: "En tanto que soy, me es necesario estar en alguna parte. Ahora bien, no puedo estar en alguna parte en tanto que «yo» puramente espiritual [...]. Pero no se puede decir de un «yo» puramente espiritual dónde está, ni que, en general, esté en alguna parte" ( $P P$, p. 60). 
"cuerpo volitivo", al cuerpo como "órgano del deseo", de la volición, del querer. Tal cosa sucede en la medida en que el cuerpo propio aparece como el único "objeto" inserto en el mundo que admite ser movido de forma directa e inmediata por la voluntad del sujeto; rasgo que, no obstante, tampoco implica que el cuerpo sea contemplado en términos de mero instrumento que el Yo controla gracias al dominio volitivo ejercido sobre él. Así es como la conciencia de los "poderes" propios en general (mi "yo puedo") se muestra como un saber de sí "esencialmente corporal". ${ }^{32}$ De hecho, el cuerpo subjetivo se identifica hasta tal punto con ese "poder" que, en el hipotético caso de verse privado de tal facultad (en caso de "no poder" actuar), no subsistiría como "cuerpo no actuante", sino que perdería ya el estatus mismo de "cuerpo propio", es decir, dejaría de existir como tal cuerpo.

El cuerpo propio se revela ahora, a la luz de todo lo indicado, como el núcleo organizador en torno al cual se estructura y vertebra la disposición del mundo y que permite al sujeto situarse y orientarse en él. Un "centro de orientación" que se erige, pues, al decir de Patočka, como "el punto cero del sistema de referencias que el hombre porta consigo o, más bien, que él mismo es". ${ }^{33}$ La totalidad de los objetos que pueblan el mundo se disponen y ordenan, pues, en conformidad con el cuerpo propio en la medida en que es éste el elemento que aporta la espacialidad originariamente organizada según los contrastes binarios "derecha-izquierda", "arriba-abajo", "cerca-lejos", etc. ${ }^{34} \mathrm{Al}$ abrir y disponer así el espacio primigenio, el cuerpo adopta constitutivamente el rol de "centro de orientación en medio de las cosas y por relación a ellas". ${ }^{35}$ Un papel ontológico que redunda en el hecho de que la epifanía del cuerpo "en tanto que punto cero rodeado de una periferia", ${ }^{36}$ propicie que el mundo -la totalidad de lo que es- comparezca ante nuestra mirada mediante una donación de orden "perspectivístico", esto es, en una estructura determinada por ese modo de aparecer el cuerpo propio como matriz central de lo dado. ${ }^{37}$ Ese "perspectivismo" de la corporeidad es el rasgo que incardina inmediatamente todo objeto que ingresa en el horizonte fenomenológico en las coordenadas espaciales marcadas por la ubica-

32 En referencia a los campos sensoriales que el Yo posee y al campo de acción conjuntamente aprehendido en ellos, Patočka señala, en sus Lecciones sobre la corporeidad, que: "La corporeidad propia, que se manifiesta ella misma en los campos sensoriales, ejerce por otra parte, en tanto que «yo puedo» y «yo hago» continuo, una acción sobre las cosas comprendidas en el interior de tales campos y, por tanto, igualmente sobre sí misma" (PP, p. 62).

33 Patočka, J., Qu'est-ce que la phénoménologie?, Grenoble, Millon, 2002, p.92. En lo sucesivo QLP.

34 Compárese esta idea con lo expuesto por Husserl en Ideen II: "Todo ser espacial aparece necesariamente de tal modo que aparece más cerca o más lejos, como arriba o abajo, como a la derecha o a la izquierda. Ello vale respecto de todos los puntos de la corporeidad aparente, que a su vez tienen, en relación unos con otros, sus diferencias con respecto a esta cercanía, a este arriba y abajo, etc. [...]. Ahora bien, el cuerpo tiene para su yo el distintivo peculiar de que porta en sí el punto cero de todas estas orientaciones [...]. Así, todas las cosas del mundo circundante poseen su orientación relativamente al cuerpo, tal como todas las expresiones de la orientación llevan consigo esta referencia" (HUSSERL, E., Ideas relativas a una fenomenología pura y una filosofía fenomenológica. Libro segundo: Investigaciones fenomenológicas sobre la constitución, México, UNAM, 1997, p. 198).

$35 Q L P$, p. 92.

$36 \quad P P$, p. 62.

37 En la octava de sus lecciones de Introducción a la fenomenología de Husserl, Patočka aclara la relación existente entre "corporalidad", "orientación" y perspectivismo" del siguiente modo: "Prosiguiendo nuestras observaciones, descubrimos que el cuerpo sensitivo es simultáneamente un centro de orientación, el punto cero a partir del cual se proyecta toda perspectiva sobre las cosas. El cuerpo y las cosas forman juntos un sistema, una estructura estable de la cual no puede ser sustraído ningún término. Las cosas remiten al cuerpo propio en tanto que centro sin el cual las perspectivas y su síntesis serían imposibles” (IPH, p. 186). 
ción central del ego corporal en el contexto del campo perceptivo. Todo aparecer de algo en general remite, pues, al Yo, se orienta hacia el sujeto corporalmente encarnado disponiéndose conforme a las categorías espaciales de orden binario anteriormente aludidas, es decir, por ejemplo, según su mayor o menor volumen de "cercanía" y "alejamiento" con respecto a tal sujeto. Es esta relación "perspectivísticamente" dada entre sujeto encarnado y mundo la que permite a Patočka redefinir el significado propio de las nociones de "mundo" y de "Yo", de tal modo que: "El mundo se descubre ante mí como una red cuyo centro soy yo. Es decir, que yo, el centro del cual irradian tanto mi receptividad como mi actividad, soy en mi corporeidad -en la acción que ejerzo- el presupuesto de la aparición del mundo". ${ }^{38}$

El ego encarnado se descubre a sí mismo, de esta forma, como matriz misma del aparecer del mundo, pero, no obstante, su propia dinámica originaria, su corporeidad primigenia, no aparece de modo efectivo en la esfera de lo dado, no se da como fenómeno, sino que constituye lo que Patočka designa como "tarea ciega de nuestra esfera fenomenal". ${ }^{39}$ Así, muy al modo de lo que sucede en referencia al Sein heideggeriano, la conditio posibilitatis de toda posible mostración no se muestra. 1 presupuesto que posibilita el aparecer de aquello que aparece no aparece él mismo en absoluto; el horizonte que posibilita toda hipotética manifestación se hurta y repliega a la hora de manifestarse. Es debido a tal ausencia y retracción que la vida corporal del sujeto -aquella misma en virtud de la cual éste se sitúa en el horizonte mundano, en la vecindad de los objetos que lo habitan y proyectando su actividad práctica sobre ellos- es esencialmente "una existencia no entre, sino más allá de las cosas y hacia ellas". ${ }^{40}$ ¿En qué consiste, pues, propiamente la peculiar posición espacial del sujeto así afincado entre las cosas? Patočka responde a esta cuestión identificando "espacialidad" y "corporeidad propia" (definida por su actividad y por su carácter "subjetivo"), de suerte que es esta última la que nos facilita el acceso a los objetos mundanos y la que establece un vínculo o nexo esencial entre las cosas y nosotros: "estamos en el espacio mediante el movimiento esencial de nuestra vida intrínsecamente corporal". ${ }^{41}$

De este modo, lejos de tratarse de un mero "momento empírico" susceptible de ser añadido de forma más o menos contingente a nuestro ser activamente realizado, la corporeidad se muestra ahora como aquella instancia que posibilita de manera única la "realización" o "ejecución" efectiva de aquel ser que efectúa su vida, que vive con vistas a su propio ser. Y ello porque la panoplia de posibilidades que se despliega constantemente ante un ser que "vive antes de sí mismo", proyectándose sobre potencialidades, únicamente admite ser realizada a través de las funciones corporales. Sólo tales funciones permiten actualizar aquellas

\footnotetext{
$P P$, p. 62.

$P P$, p. 68.
}

$40 \quad P P$, P. 68. De hecho, "Nosotros estamos en el espacio en tanto que subjetivamente corporales, por la realización del movimiento no solamente en medio de las cosas, sino, más originariamente, hacia las cosas que no es un accidente que nos sobrevenga, sino aquello que somos" (PP, p. 93).

${ }_{41} P P$, p. 93. Esta esencial relación establecida por Patočka entre corporeidad, subjetividad y movimiento es puesta concisamente de relieve por Renaud Barbaras en los siguientes términos: "pour Patočka, le fait originaire n'est plus l'effort comme dualité d'une impulsión et d'une résistance, mais le mouvement comme épreuve de l'unité entre le moi et la corporeité. En d'autres termes, le cogito doit être pensé comme cogito moteur, ce qui revient à dire que l'articulation du «je pense» et du «je suis» s'effectue au sein du mouvement, en est pour ainsi dire l'oeuvre. On rencontré ici une nouvelle figure, peut-être plus originaire, du cogito" (Barbaras, R., L'ouverture du monde. Lecture de Jan Patočka, Chatou, La Transparence, 2011, pp. 147-148). 
posibilidades a las cuales el sujeto se adhiere en cada momento con diversos grados de intensidad. De forma análoga, únicamente la corporeidad propia (mediante los campos sensoriales) aparece como instancia investida de la capacidad de favorecer "el encuentro con los entes que son de otro orden que nuestra vida, así como con aquellos que, al igual que nosotros y con nosotros, viven realizando su ser [los otros]". ${ }^{42}$ Cumplir, realizar, consumar las propias posibilidades de modo efectivo, real, es algo solamente posible corporalmente, por mediación del cuerpo. Algo dado con exclusividad a un ser cuyo estatuto fenomenológico y ontológico es el de una subjetividad viviente corporalmente encarnada. ${ }^{43} \mathrm{Y}$ es debido a ello que a nuestra existencia le pertenece esencialmente el movimiento o incluso, como afirma explícitamente Patočka, "es, por toda su naturaleza, movimiento". ${ }^{44}$ Renaud Barbaras, en su extenso estudio sobre "fenomenología de la vida", ha visto y consignado con acierto esta esencial vinculación de la corporalidad tanto con el ejercicio de las posibilidades propias como con el movimiento inherente a éste en el marco de la fenomenología de Patočka. ${ }^{45}$ La directriz fundamental que marca el sentido de nuestro movimiento surge, pues, siempre desde la corporalidad. ${ }^{46}$ En definitiva, conforme a la que bien puede considerarse última palabra del filósofo checo en lo concerniente a la cuestión que nos ocupa (dado que fue formulada en las lecciones de Introducción a la fenomenología de Husserl dictadas a finales de los sesenta), "el cuerpo propio, si es efectivamente un objeto, es un objeto que posee un sentido, incluso que es igualmente un sentido, capaz de conferir sentido, que se mueve y existe únicamente en el campo del sentido". ${ }^{47}$

$42 \quad P P$, p. 97.

43 Así pues, "Nuestra existencia es esencialmente corporal, encarnada, y nuestro cuerpo propio, en tanto que cuerpo viviente, cuerpo capaz de moverse, cuerpo sobre el cual tenemos poder, es el fundamento de toda vida de experiencia. El poder sobre el cuerpo es el ser que es en su totalidad comprensión de sus posibilidades más fundamentales, sin el cual la vida de experiencia que se comprende a sí misma no sería posible" $(P P$, p. 107).

$44 \quad P P$, p. 107. Un rasgo que no ha pasado desapercibido a la mirada de Edward F. Findlay, para quien: "It is the focus on the corporeity of our existence that leads Patocka to movement, for our awareness of ourselves as bodily is an awareness of our mobility. Our experience is that of corporeal beings, and thus of beings in motion. We live in the world by engaging with it, by involving ourselves and by realizing our possibilities through our actions" (Findlay, E. F., Caring for the soul in a postmodern age. Politics and Phenomenology in the Thought of Jan Patočka, Albany, State University of New York Press, 2002, p. 42).

45 "Si tomar en consideración la corporalidad es lo único que permite conferir a la existencia su pleno significado, por su parte este acercamiento desde el punto de vista de la existencia repercute en el sentido de la corporalidad y permite conferirle su auténtico sentido del ser: la corporalidad es posibilidad de moverse. Abordar la existencia desde el punto de vista de su efectividad significa integrar en ella la corporalidad como dimensión primera, y, por su parte, comprender el cuerpo a partir de la existencia es definirlo como movimiento. En otros términos, gracias a que aborda la intramundaneidad desde el punto de vista existencial, a saber: como lo que fundamenta el poner en práctica las posibilidades, Patočka accede al auténtico sentido del ser del cuerpo" (Barbaras, R., Introducción a una fenomenología de la vida. Intencionalidad y deseo, Madrid, Encuentro, 2013, p. 159).

46 En El mundo natural y la fenomenología, Patočka muestra sus cartas al respecto de modo inequívoco: "cada uno de nuestros «movimientos físicos» forma en realidad parte de ese movimiento omniabarcador global que somos - puesto que nuestros movimientos son esencialmente movimientos de un «cuerpo subjetivo», o bien su significado está marcado indeleblemente por un cuerpo tal-. Por lo mismo, todo lo que se nos da se integra a una «orientación» que, siendo esencialmente corporal, puede designarse como movimiento" (MEH, p. 52). Novotný indica el nexo esencial entre este movimiento somático y la alteridad del otro en los siguientes términos: "Dans le passage du mouvement du corps physique au mouvement du corps propre et inversement, le mouvement joue un rôle dans un autre sens encore: le corps (Körper) vivant ne devient corps propre humain, sujet du vécu, qu'à travers l'acceptation par d'autres humains. Le milieu de ce mouvement est l'affectivité, l' "é-motio-nalité»" (GH, p. 76).

$47 \quad I P H$, p. 183. 
Esta esencia de la corporalidad residente en la encarnación y donación de sentido constituye un rasgo fenomenológico que no puede sino escapar a la consideración de la ciencia, siendo, de hecho, sistemáticamente preterida por la biología y pasada por alto por la física.

En el ensayo Fenomenología y metafísica del movimiento, Patočka vincula explícitamente la donación de sentido (en general) con la relación originaria con el mundo y, por tanto, con el cuerpo en tanto que instancia garante de ésta. Así, del hecho de que toda dispensación de sentido (orientación, ubicación, acción y situación) se encuentre necesariamente transida de corporeidad -se efectúe a través de los mecanismos del cuerpo propio- Patočka deduce precisamente su postulado inicial: la existencia de un cuerpo "subjetivo". Y ello por la palmaria razón de que tanto la donación como la recepción de sentido (o su simple consumación) ha de constituir inevitablemente siempre un acontecimiento relacionado con un sujeto viviente y abierto a la experiencia en general. Así pues, de ello se deriva que no puede haber solamente un cuerpo "vivido" o "experimentado" (objetivo), sino que ha de darse también y más esencialmente un cuerpo "experimentante" (subjetivo); cuerpo éste no susceptible de ser captado o aprehendido objetivamente, pero que, aun así, según el concluyente dictamen patočkiano, "es un hecho". Tanto es así que la propia existencia fáctica del cuerpo-objeto prueba ya la del previo cuerpo subjetivo, ya que, al decir de Patočka, en ausencia del cuerpo "experimentante" el cuerpo experimentado (aquel que admite ser descrito y analizado fisiológicamente) resultaría simplemente imposible o, a lo sumo, "sería posible considerarlo como un aparato registrador y realizador, pero no podríamos, como efectivamente lo hacemos, verlo como un compañero o reconocernos nosotros mismos en él". ${ }^{48}$

Esta postura, nótese bien, supone una auténtica redefinición tácita de la noción misma de subjetividad, particularmente un socavamiento del concepto más o menos "tradicional" acerca de la misma. En efecto, la subjetividad, habida cuenta de la mutua imbricación constatada entre lo subjetivo (que siempre se da encarnado) y lo corporal (que es también subjetivo), aparece a esta luz bajo la forma de un cuerpo propio que "va siempre por delante de una nueva formación y donación de sentido" ${ }^{49}$ De este modo, la subjetividad encarnada desplaza y sustituye ahora al ego trascendental a la hora de localizar la verdadera sede de las "síntesis de experiencia", es decir, el fundamento de toda vivencia empírica de lo real. Lejos de ser nuestras cogitationes -las efectuaciones noéticas derivadas del Yo- las que nos insertan en el horizonte del mundo de manera original, tal función es cumplida realmente por el cuerpo propio en su calidad de "cuerpo subjetivo" constitutivamente refractario a dejarse resolver en el pensamiento reflexivo. ${ }^{50}$ Es, pues, la corporalidad subjetiva

$48 \quad P P$, p. 23.

$49 P P$, p. 16. A este respecto, concluye Patočka: "En el interior de este ciclo continuo de donación de sentido, sería necesario aún trazar en particular los contornos del cuerpo subjetivo, es decir, del cuerpo propio, no en tanto que objeto, sino en tanto que viviente, actuante, percipiente, encontrándose inmediatamente en relación con los objetos. El cuerpo en tanto que sujeto: esta paradoja es, sin embargo, un fenómeno sin el cual nunca podría comprenderse la visión, la audición, la percepción en general, ni tampoco la acción humana" ( $P P, \mathrm{pp} .16-17)$.

50 Sobre este punto, aclara nuevamente Novotný: "En ce sens, le corps propre (Leib) -à la différence du corps physique (Körper) - n'existe que dans le mouvement subjectif. On voit là derechef, très clairement, le point sur lequel Patočka veut se démarquer de Husserl: le «je fais» n'est pas un vécu pur et simple, mais d'ores et déjà une réalité vécue. Le sum incarné est un sujet qui ne se fonde pas sur le «moi» des actes au sens de «vécus», saisissable réflexivement, car l'agir du sum est l'agir d'un corps de chair, ce sont des mouvements dont le moteur, le sujet, n'est pas un pur ego, mais, au contraire, précisément le corps propre" (GH, p. 64). 
la que lleva a cabo las síntesis empíricas haciendo uso para ello de su capacidad de automovimiento, y no el Yo puro. Esto es lo que significa fundamentalmente que el cuerpo propio es la raíz y la fuente de todo sentido.

Así pues, habida cuenta de la totalidad de lo hasta aquí expuesto en referencia al cuerpo como punto nuclear de ubicación y como sede del sentido, cabría formular en este punto la típica cuestión que trata de elucidar si, en última instancia, nosotros "tenemos" un cuerpo (al modo tradicionalmente postulado por la tradición "dualista" desde Platón a Descartes) o si, más bien, sería necesario afirmar con mayor exactitud que "somos" realmente un cuerpo (a la manera propuesta por el célebre dictum nietzscheano). Patočka introduce también esta disyuntiva mediante el planteamiento de la pregunta acerca de si "el cuerpo propio es idéntico al sujeto"; cuestión que, a su juicio, admite una doble respuesta. Por un lado, la del cartesianismo, en la cual "el ego es un puro espíritu" y "el espíritu, el ego, tiene un cuerpo del cual dispone como de un instrumento al servicio de su incorporeidad y de su libertad esenciales" ${ }^{51}$ Por otro, la "solución" nietzscheana, conforme a la cual: "el cuerpo no es una cosa que tengo, sino aquello que soy. Yo no soy cuerpo y espíritu, sino integralmente cuerpo. Hablando del cuerpo, Nietzsche no entiende un simple objeto objetivamente fisiológico, sino más bien el sujeto corporal" ${ }^{52}$ Abordada desde la perspectiva del análisis fenomenológico, la cuestión es, pues, ¿“tenemos" o "somos" un cuerpo? La respuesta de Patočka al respecto se condensa en la fórmula según la cual yo puedo decir que "yo soy mi cuerpo", pero "la inversa no es verdadera: mi cuerpo no es mi ego". ${ }^{53}$ Podemos, pues, identificarnos legítimamente con nuestro cuerpo propio en la medida en que éste nos pertenece y nos corresponde hasta tal punto que no podríamos existir en su ausencia, es decir, en cuanto formamos una unidad con él. Pero considerado "en sí mismo", con prescindencia de su referencia a nuestro ego, el cuerpo deviene irremediablemente aquello que Patočka llama "una abstracción privada de vida". Una entelequia fenomenológica que únicamente cobra entidad e identidad propias en virtud de su ligazón al Yo. En este sentido, "puedo decir que soy mi cuerpo o también que lo tengo, pero me es imposible afirmar en el mismo sentido que mi cuerpo «me tiene», que él es mi ego". ${ }^{4}$

En efecto, si bien es cierto que en múltiples ocasiones el cuerpo determina al sujeto encarnado que ha de padecer su influencia, esto no significa que actúe con una espontaneidad "libre" capaz de dominar al ego y de imponerse a él. Tal aparente preeminencia sólo es el fruto de un préstamo derivado del hecho de subordinar o alienar el ego al cuerpo de manera intencionada y provisoria. Así pues, si la cuestión

\footnotetext{
IPH, p. 191.

$I P H$, p. 191.

$53 \quad I P H$, p. 194. Gabriel Marcel observa pertinentemente acerca de este asunto: "la cuestión esencial es aquí la de tener. Creo que no es difícil ver que el lazo que me une al cuerpo es en realidad el modelo, no expresado pero sentido, con el que se relaciona toda posesión [...]. La verdad es más bien que en el interior de toda posesión, de cualquier modo de posesión, hay una especie de núcleo sentido, y ese núcleo no es otra cosa que la experiencia -irreductible a términos intelectuales- del lazo por el cual el cuerpo es mío" (Marcel, G., El misterio del ser, Barcelona, Edhasa, 1971, p. 87). En Position et aproches concrètes du Mystère Ontologique (1933), Marcel ya puntualizaba que "La unidad indivisible que expresamos siempre de forma inadecuada mediante fórmulas tales como: tengo un cuerpo, me sirvo de mi cuerpo, siento mi cuerpo, etc...es exterior a todo análisis, y en modo alguno se podría reconstruir por vía sintética a partir de elementos que le serían lógicamente anteriores; tal unidad no sólo está dada, sino que yo diría que es donante" (Marcel, G., Aproximación al misterio del Ser, Madrid, Encuentro, 1987, p. 38).

${ }_{54} I P H$, p. 194.
} 
es "¿soy mi cuerpo o tengo mi cuerpo?”, la fenomenología -señala Patočka- contesta mediante el planteamiento de otra cuestión: “¿qué significa aquí "ser”, yo soy" y "tengo?", lo cual equivale a distinguir nítidamente entre el propio "ser" entendido como aquello con lo cual el sujeto no puede evitar identificarse (su ego) e, inversamente, como aquello que no se adecua nunca totalmente a su sí-mismo. En este último caso, yo soy, además de mí-mismo, también aquello que tengo; aquello sin lo cual me resultaría vedado el acceso a lo que yo no puedo "ser", sino solamente "poseer". ${ }^{55}$ En Cartesianismo y fenomenología (1976), uno de sus últimos estudios, Patočka se refiere a esa "corporalidad que hace posible el trato entre los seres y les permite comprenderse entre ellos", esto es, a aquella que caracteriza como "corporalidad de los gestos, los signos y la expresión", enfatizando el hecho de que "no se trata, pues, de una corporalidad que nosotros somos, sino de una sin la que nosotros no somos, la existencia y desarrollo de la cual hace posible nuestro propio comprender en una extensión y profundidad que en cuanto sujetos individuales nunca alcanzaríamos". ${ }^{56}$

Esta corporalidad que posibilita la relación intersubjetiva, el "trato" con los otros, es justamente el hito que marca la transición desde la fenomenología del cuerpo a la fenomenología de la alteridad en el pensamiento maduro de Patočka. Un tránsito demandado por la intuición según la cual la "objetividad" hacia la que se dirige, en general, la existencia humana es fundamentalmente aquella representada por la socialidad, por la comunidad con los otros, por el trato recíproco con el prójimo, y no tanto la "objetividad" encarnada en las cosas. En primer y último término, nos interesan, pues, en mayor medida las personas que los objetos, y éstos nos importan en la medida en que remiten a los sujetos personales y se relacionan con ellos. Así pues, nuestra situación existencial se encuentra impregnada y transida de lo que Patočka caracteriza como "un esencial carácter personal", lo cual significa que existir -al modo heideggeriano- como "ser-en-elmundo" implica esencialmente existir como sujeto encarnado y en compañía de otros sujetos igualmente encarnados con los que se comparte un mismo mundo. Esto es lo que esencialmente quiere decir Renaud Barbaras cuando, en referencia a la "proto-estructura je-tu-ça" en Patočka, señala que "el pronombre personal es la ley primordial de la experiencia. ${ }^{57}$ En las Lecciones sobre la corporalidad, Patočka deja meridianamente claro el sentido de este nexo esencial entre cuerpo

55 Acerca de este aspecto crucial, Michel Henry, el más descollante adalid del "cuerpo subjetivo" en el marco de la fenomenología contemporánea - una voz singularmente acreditada, por tanto-, indica significativamente: “A la afirmación «yo tengo un cuerpo» conviene, pues, oponerle esta otra afirmación más originaria: «yo soy mi cuerpo». Incluso un enunciado así corre el riesgo de resultar ambiguo si frente al rigor del análisis ontológico se prefieren las sutilezas y los verbalismos de una filosofía de la ambigüedad. «Yo soy mi cuerpo» no significa «yo soy mi cuerpo y a la vez no lo soy», "yo he de serlo en el modo en que no lo sea», etc. [...], sino que significa más exactamente: el ser originario de mi cuerpo es una experiencia interna trascendental y, por tanto, la vida de este cuerpo es un modo de la vida absoluta del ego. «Yo tengo un cuerpo» significa: un cuerpo trascendente también se me aparece y se me da como sometido, en una relación de dependencia, al cuerpo absoluto que [...] funda tanto este cuerpo objetivo como la relación de posesión que lo une al ego" (FFC, pp. 269-270).

$56 \quad M E H$, p. 226.

57 'Il n'y a de constitution de l'espace qu'à partir d'un dedans non spatial, que la polarité ici-là-bas repose sur la polarité je-tu-ça, bref que le pronom personnel est la loi primordiale de l'expérience [...]. Il faut seulement souligner que, dans la mesure où le noyau de cette ouverture au monde est la relation à l'autre qui $m$ 'accepte, le monde a d'abord le visage de l'autre: comme Husserl l'affirmait, le premier autre, c'est autrui"' (Barbaras, R., Le mouvement de l'existence. Études sur la phénoménologie de Jan Patočka, Chatou, La Transparence, 2007, pp. 103-104). 
propio y referencia a la alteridad de los otros: "la experiencia personal, la situación personal, es únicamente posible, también ella, en tanto que corporal, encarnada. Es solamente en virtud de la mediación por el cuerpo propio que es posible la existencia en la reciprocidad, consciente del carácter especular de la experiencia, que es el fundamento de nuestra vida entre y con los otros". ${ }^{58}$ Veamos en lo sucesivo en qué términos concretos se da fenomenológicamente tal flujo intersubjetivo mutuo acontecido entre sujetos comúnmente referidos a la misma "objetividad".

\section{La vida con los otros: un co-proyecto de naturaleza especular}

Patočka hace referencia, como acabamos de ver, a un cierto carácter "especular" propio de la totalidad de nuestra experiencia; también, pues, de nuestra experiencia del otro. ¿En qué sentido -cabría interrogar al respecto- se habla en este contexto de un speculum y qué es exactamente lo reflejado en ese "espejo" de lo empírico? Una vez más, es el cuerpo propio el elemento que viene a jugar aquí un rol crucial. En efecto, Patočka parte aquí del supuesto según el cual "La experiencia de la segunda persona, la realización del tú, presupone la experiencia de sí en primera y tercera persona".${ }^{59}$ Establecido este marco fenomenológico, constatar empíricamente la noción de "tú", es decir, verificar al otro en la experiencia propia, no resultaría factible si no se diese ya algo "en lo cual" tiene lugar la donación del otro. Una dimensión "objetiva" en cuyo interior le sea dada al sujeto la "otra subjetividad", el tú que encarna privilegiadamente la irreductible alteridad del otro. "Objetiva" decimos, pues ese ámbito de donación de los otros al ego no puede mostrarse como una instancia de orden "subjetivo", dado que la subjetividad propia se da en tanto que elemento viviente, mientras que la ajena ("presentificada", la llama Patočka siguiendo de cerca a Husserl) comparece como algo esencialmente "otro" y "extraño". Patočka extrae de ello una determinante conclusión, a saber: "la presencia del otro como tal en mí es, pues, necesariamente asubjetiva" ${ }^{60}$ ¿Qué quiere decir aquí tal término? Sencillamente (y ello aclara el sentido "especular" de la experiencia del prójimo) que si la epifanía del otro tiene lugar de tal modo que el Yo la percibe como si se tratase de la suya propia dada en el exterior, "invertida como en un espejo, entonces esta aparición en el afuera debe igualmente serme dada como algo asubjetivo, es decir, que ella se despliega necesariamente en el fenómeno de mi cuerpo-objeto". ${ }^{61}$

$58 \quad P P$, pp. 92-93.

59 IPH, p. 199. En el ensayo fragmentario Fenomenología del cuerpo propio, Patočka incide nuevamente sobre la secular preeminencia otorgada la "tercera persona" al abordar la cuestión del cuerpo. En este sentido, escribe: "Es claro que el cuerpo, tal como interesa a todos estos pensadores [antiguos] es el cuerpo objetivo, el cuerpo para la mirada, el cuerpo extraño: en el fondo, el cuerpo de una tercera persona del cual se preocupa teóricamente [...]. En el marco del atomismo, sobre todo, el cuerpo y el «alma» son situados en el mismo plano, el problema del alma deviene parte integrante del problema del cuerpo, siendo éste considerado como una cosa objetiva con los procesos en tercera persona que se desarrollan en su interior o que lo implican [...]. En relación con ello, el cuerpo en tanto que viviente y subjetivo no es privilegiado en modo alguno con respecto a su correlato, con respecto a la psuchè, a aquello que traducimos como «alma». La psuchè se distingue asimismo de su posteridad conceptual moderna en la medida en que le falta la subjetividad propia. Desde el punto de vista griego y antiguo en general, la psuchè es neutra en relación con los pronombres personales" (Patočka, J., Le monde naturel et le mouvement de l'existence humaine, Dordrecht, Kluwer Academic Publishers, 1988, pp. 140-141).

$60 \quad I P H$, p. 199.

$61 \quad$ IPH, pp. 199-200. 
Esta "especularidad" de la experiencia (mediada por el cuerpo propio) que propicia el recíproco "ser-con-otros" 62 aparece, a esta luz, como fundamento de nuestro esencial carácter "proyectual". La mayor parte de nuestros proyectos son, de hecho, "co-proyectos", planes y propósitos que remiten a los otros, los implican o se desarrollan bajo su contemplación. Es merced exclusivamente al hecho de que la vida de cada uno se configura irremisiblemente como "vida con el otro", como "ser-haciael-otro", que cada sujeto se constituye originariamente ${ }^{63}$ ante sí mismo como algo susceptible de ser abordado "en el mismo carácter de ser" que el resto de las cosas. De este modo es como "se completa nuestra localización en el mundo uno y común a través de los otros y en ellos". ${ }^{64}$ En definitiva, desde la perspectiva asumida por la fenomenología "asubjetiva" patočkiana, el sujeto humano se presenta como ente definido en la totalidad de su ser más profundo por su rol de protector del otro: por su constitutiva condición de dispensador de calidez, creador de seguridad, donante de unidad y cercanía mutua en referencia al ser de los otros. En su esencia más íntima, el hombre es, remarca Patočka, "tributario del otro hombre". ${ }^{65}$

De hecho, en el desvelamiento mismo del trato cotidiano con las cosas -trato que soslaya la captación del mundo como "mundo"- subyace ya una larvada manifestación del perenne vínculo que relaciona al sujeto con su prójimo. Los proyectos en los cuales se embarca e implica cada sujeto particular únicamente se revisten de significado mediante la reciprocidad derivada de la compenetración con los otros. El contacto con el otro -subraya Patočka- constituye el centro de nuestro mundo natural y humano, aquello que confiere a ambos su significación, su contenido y aun la totalidad de su sentido. El medio humano es configurado única y exclusivamente en virtud del contacto y la cercanía con el prójimo. Las propias facultades perceptivas del sujeto, aquellas que actúan como cauce que posibilita su contacto con lo real sensiblemente captado, resultan investidas de significación solamente merced al modo en que es asumida de modo inmediato la presencia conjunta de los otros junto a nosotros en un mismo horizonte ontológico. Pero inversamente, tampoco la percepción sensible se halla primordialmente orientada, como pudiera prima facie parecer, hacia los elementos mundanos (objetos, cosas), sino hacia aquel ámbito en donde moran los otros hombres. La captación representativa de un determinado objeto situado, al modo del "esto" hegeliano, "aquí" y "ahora" ante mí, no ha de ser necesariamente la de otro sujeto, pero, en caso de no serlo, Patočka detecta ahí una ausencia o carencia fundamental: "el objeto propio en el que estamos no es nunca un ello ni un él, sino un tú. El tú es siempre un objeto próximo, al alcance; es con quien hablamos, no acerca de quien hablamos". ${ }^{66}$

Aparece aquí nuevamente la dialéctica especular entre el otro y yo, dado que realmente yo me aprehendo y percibo a mí mismo de modo originario fundamental-

62 Un "ser-con" que, advierte Patočka, conviene no identificar con Sorge alguna: "El ser-con no es preocupación, aunque el Mitdasein se conoce en la preocupación. El ser-con es en tan escasa medida preocupación, que la preocupación es el Dasein cotidiano [...]. Con todo, el Mitdasein no está únicamente en la preocupación: se sitúa más profundamente. El ser-con es algo último, el ser en la co-presencia, en el-ser-arrojado-el-uno-con-el-otro: el ser propio como conteniendo a otro y como contenido en otro; el otro es en mí y yo soy en él” (PP, p. 250).

63 Destacamos el adverbio "originariamente" teniendo bien ante la vista el hecho de que, como señala Patočka, "es actualmente real para nosotros aquello que no podrá jamás sernos dado en original: por ejemplo, la experiencia del otro en tanto que otro" ( $P P$, p. 65).

64 PP, p. 93.

$65 \quad$ PP, p. 109.

$66 \mathrm{MEH}, \mathrm{p} .38$. 
mente a través de la mediación representada por las actitudes, conductas y reacciones de los otros con respecto a mí. En esta dialéctica de la alteridad recíprocamente captada y compartida gracias a la cual cada ipseidad particular se acerca a sí misma, radica a ojos de Patočka "lo más importante del drama de la vida". Y ello porque es únicamente en el interior de este milieu intersubjetivo e interhumano donde cada sujeto individual actualiza su esencia como ser viviente ligado a los otros aun con anterioridad a su trato familiar con los objetos que pueblan el mundo. Una hipotética existencia singular privada de la referencia los otros, un Robinson sin Viernes alguno, aparecería como el sinsentido par excellence. Así pues, el quehacer fundamental propio de la vida humana no consiste sino "en la búsqueda y descubrimiento del otro en uno mismo y de uno mismo en el otro" ${ }^{67}$ lo cual equivale a la tentativa orientada a traer a la superficie aquella interioridad subjetivo-vital que subyace en lo profundo y late permanentemente bajo todo fenómeno. En el interior del éter del sentido, el sujeto y el otro se revelan el uno al otro de modo recíproco, en su objetivo cara-a-cara, pero el pathos afectivo que los lleva a descubrirse mutuamente hunde sus raíces en una dimensión radicalmente previa a toda objetividad. El originario aherrojamiento al otro impregna y tamiza, pues, la totalidad de los vínculos hipotéticamente asumibles por el sujeto, a la vez que se revela como el origen último de toda "mundanidad" y de toda inserción en el mundo "natural". De ahí que Patočka condense esta protoraigambre primigenia de cada cual en la alteridad del otro, en la sugestiva sentencia conforme a la cual "los otros son el hogar originario". ${ }^{68}$

\section{Conclusión}

De todo lo expuesto se desprende que, desde la perspectiva de la "fenomenología asubjetiva", se da un vínculo esencial entre corporalidad y alteridad. Este nexo crucial se nutre del hecho de que, al decir de Patočka, "la comunicación intersubjetiva tiene lugar exclusivamente por la intermediación del cuerpo-objeto" ${ }^{69}$ Esto significa que el rol crucial del cuerpo objetivo se localiza en esta labor mediadora que lo convierte en auténtico "vehículo de la socialidad", en cauce único a través del cual nos es dado el acceso a la alteridad de los otros. En suma, la corporalidad aparece como el único salvoconducto susceptible de dejarnos expedito el camino hacia nuestro "hogar originario". ${ }^{70}$ Nótese bien, bien embargo, que, como ya apuntamos con anterioridad, en la fenomenología patočkiana el cuerpo que propicia nuestra franquía hacia el otro no es propiamente un cuerpo "subjetivo", "eidético" o "trascendental", sino -como el filósofo checo apunta explícitamente- el "cuerpo-objeto" externo que es sensiblemente percibido, tanto por el prójimo como por el sujeto encarnado mis-

$67 \quad M E H$, p. 40.

${ }_{68} M E H$, p. 41. Así, de forma igualmente gráfica, Patočka escribe: "El otro (y, en consecuencia, yo mismo también para el otro) es primeramente en quien echamos raíces y por cuya mediación echamos raíces" (MEH, p. 43).

69 QLP, p. 112.

70 Como señala pertinentemente Ilja Srubar en referencia al primero de los tres "movimientos de la existencia humana" postulados por el fenomenólogo de Turnov, "Patočka nomme cette phase le mouvement de l'ancrage, et il designe par là le procès d'insertion originaire du sujet dans son monde par la relation à d'autres. C'est un procès d'appatriement de l'homme dans le monde par sa socialité, par son acceptation par les autres, procès au cours duquel se développe la «structure originaire» primaire de mon monde" (Srubar, I., "Phénoménologie asubjective, monde de la vie et humanisme", en Tassin, E. y Richir, M. (eds.), Jan Patočka: philosophie, phénoménologie, politique, Grenoble, Millon, 1992, pp. 93-94). 
mo. ${ }^{71}$ Desde el prisma fenomenológico adoptado por Patočka, la epifanía de la alteridad del otro ante la mirada del Yo ha de asumir indefectiblemente -como cabía de nuevo esperar- un carácter "asubjetivo" a la vez que especular: "Si [la presencia del otro] se produce de tal manera que yo la capto como mi propia aparición en el exterior, invertida como en un espejo, esta aparición en el afuera debe serme igualmente dada como algo asubjetivo. Esto equivale a decir que ella se desarrolla necesariamente en el fenómeno de mi cuerpo-objeto". ${ }^{72}$

En este sentido, la "fenomenología asubjetiva" de Patočka subestima y pasa por alto la posibilidad -brindada por la "fenomenología de lo inaparente" aludida por el último Heidegger- de una intersubjetividad sin cuerpo: de un acceso a la alteridad del otro no necesariamente mediado y tamizado por la presencia del cuerpo objetivo. Como apuntábamos anteriormente en referencia a Levinas, tal vez la alteridad radical del prójimo se halle más allá (o más acá) de una mera "alteridad de atributos" -como tal siempre necesariamente ligada a cualidades y propiedades de orden corporal-, a la cual precedería de manera absoluta. ${ }^{73}$ Antes que el cuerpo-objeto y sus atributos susceptibles de predicación, se da "ya desde siempre" (immer schon, diría Heidegger) esa epifanía de la alteridad irradiada por el rostro ajeno que en algún momento ha sido motejada de "fantomatique" y aceptada como tal por el propio Levinas. ${ }^{74}$ Alteridad, pues, invisible y "desencarnada", pero que acaso conmina al sujeto encarnado a la connivencia con la alteridad del otro con un volumen de pujanza sustancialmente mayor que aquel que es capaz de alcanzar su aparición "asubjetiva" mediada por el cuerpo-objeto tal como ésta es postulada por Patočka.

71 Resulta oportuno recordar aquí nuevamente las advertencias formuladas al respecto por Marc Richir cuando indica que "Este cuerpo físico, no podemos serlo [...], pero tampoco podemos tenerlo, a menos que supongamos que el sujeto de este tener sea un alma descarnada que habitara factualmente este cuerpo como el navegante su navío [...]. En la medida en que este cuerpo está instituido como aquello que, del cuerpo, es lo único real, esa institución es simbólica -siendo declarado insignificante, no pertinente, todo lo que allí no entre. Y esta situación solo puede engendrar, en los seres humanos vivos y encarnados que somos, un profundo malestar" (EC, pp. 40-41).

72 QLP, p. 103.

73 En su conversación con François Poirié, Levinas se muestra tajante en este aspecto: "Pero antes que todo atributo usted es otro respecto a mí, de otro modo, jotro absolutamente! Y es esta alteridad, distinta de la que respecta a los atributos, la que es su alteridad" (Poirié, F.-Levinas, E., Ensayo y conversaciones, Madrid, Arena, 2009, p. 79).

74 "Se dice que en Totalidad e infinito el otro aparece de manera fantasmagórica. Es necesario que el otro sea acogido con independencia de sus cualidades [también corporales], si es que debe ser acogido como otro. Si no hubiese aquí una certeza inmediata -es incluso la inmediatez por excelencia; la relación con los otros es la única que no vale sino como inmediata- el resto de mis análisis perdería toda su fuerza. La relación sería una de esas relaciones tematizables que se establecen entre objetos [o entre "cuerpos-objeto]" (Levinas, E., De Dieu qui vient à l'idée, Paris, Vrin, 1992, p. 129). 